\title{
A New Approach to Demand Response in a Microgrid Based on Coordination Control between Smart Meter and Distributed Superconducting Magnetic Energy Storage Unit
}

\author{
I. Kouache, M. Sebaa, M. Bey, T. Allaoui, M. Denaï
}

\begin{abstract}
Energy storage and demand response are becoming an increasingly valuable solution for the enhancement of stability and reliability of the electricity grid with high penetration of distributed energy sources such as wind and solar. This paper proposes an intelligent energy management scheme to allow different distributed generation sources and energy storage technologies to actively participate in demand response via the deployed smart meter infrastructure. A Distributed Superconducting Magnetic Energy Storage (D-SMES) device is integrated into the network to deliver instantaneous and large bursts of power to support the grid under shortterm disturbances. The proposed demand response-based energy management algorithm receives, via the smart meter infrastructure, the information from the electricity network such as the energy cost, upper load adjustment limit, and the State-of-Charge (SOC) of the storage system then, under very specific conditions, a decision is formulated as a control signal for charging or discharging the storage system, aiming at minimizing the total energy while avoiding any load shedding. The effectiveness of the proposed demand response approach for controlling generation, storage and demand coordination and energy cost reduction is demonstrated on a sample power system simulated in MATLAB/SimPowerSystems toolbox and evaluated under different case study scenarios.
\end{abstract}

Keyword: Smart Grid, Demand Response, Energy Storage, Distributed Generation, D-SMES, Smart Meter, Energy Management System.

\section{INTRODUCTION}

Utility grids around the globe are experiencing a transition towards more reliable, sustainable and resilient electricity systems. A key-enabler technology for this digital utility transformation is a two-way communication infrastructure across the power network [1]. Many countries have already started a large-scale deployment of smart electricity meters which offer a range of intelligent functionalities. These technologies can effectively integrate the actions of different end-users (consumers and prosumers) in order to maintain an efficient, sustainable, economically viable and secure electricity supply [2].

The growing demand for electricity worldwide, the environmental pressures, and the large-scale penetration of intermittent renewable energy sources are compromising the operation of the electricity grid and creating new technical and economic challenges for network operators [1,3]. Member States of the European Union have set themselves ambitious targets on energy efficiency, development of renewable and alternative energy resources and reduction of $\mathrm{CO} 2$ emissions $[2,4]$.

To address these energy-climate challenges, new innovative technologies and solutions are being developed. In this context, energy storage is set to play a key role in future electricity networks [5,6]. Grid-scale electricity storage can offer a number of valuable ancillary services to the network and provide multiple benefits such as grid support, balancing of variable generation from intermittent renewable energy sources and has the ability to provide centralized or decentralized responses to the changing energy requirements Electricity storage $[7,8]$ has also economic advantages over the long term for both the power industry and consumers $[9,10]$. 
In Demand Response (DR) programs, consumers are offered opportunities to monitor and manage their energy usage. DR programs encourage end-users to use green energy and adopt efficient measures to save energy, reduce their energy bills and generate revenue by exporting their excess of generation to the grid $[\underline{8}, \underline{11}]$. These new technologies must enable them to effectively integrate the actions of different users, consumers, producers and prosumers, in order to maintain an efficient, sustainable, economic and secure electricity supply $[\underline{12}, \underline{13}, \underline{14}, \underline{15}]$.

Smart Meters (SM) allow a two-way communication between the consumer and the energy supplier and are a vital step towards the transition to smart grids Smart Grid (SG) $[16,17,18]$. A Smart Meter is an advanced digital energy meter (usually electric) which can monitor, in near-real time, consumer energy usage. It has also other built-in intelligent functions for communicating and transmitting the information collected by different channels (power line, Internet, telephone) [18, 19].

In the same context, enabling technologies for the successful shift towards the future SG are being developed. Among these, energy storage is considered as a key enabling technology and is gaining momentum these recent years $[\underline{5}, \underline{20}]$. The deployment of energy storage provides multiple benefits including frequency regulation, voltage support and other important services to the network such as the unlocking of large-scale deployment of low-carbon energy, as well as the replacement of thermal power stations, the ability to provide centralized or decentralized responses for local or global constraints independence from fossil fuels, economic advantage over the long term, as an increase in the prices of these resources and that of $\mathrm{CO}_{2}$ is foreseeable $[\underline{6}, \underline{21}, \underline{22}]$.

The Superconducting Magnetic Energy Storage (SMES) is a very efficient energy storage device which stores energy in the magnetic field of a superconducting coil and is connected to a grid by means of a power electronics interface. The stored energy can be discharged into the grid when necessary $[\underline{9}, \underline{22}]$. Compared to the other energy storage systems (ESS), SMES devices have faster response time and higher efficiency $[2,21,23]$. In addition, the number of charging and discharging cycles is virtually unlimited [24]. These advantages make the SMES a potential solution for addressing the challenges the future power grids.

Distributed SMES (D-SMES) is now a quickly emerging and promising application of the proven SMES technology to support grid management and enhance power system level stability and reliability.

In this paper, an energy management methodology is proposed to coordinate the power flows among the loads, the DSMES unit and the Smart Meter device. The main objectives of the proposed energy management strategy are to enhance power quality and reliability of the electricity grid safety while optimizing energy usage and cost.

\section{CONFIGURATION AND CONTROL OF THE D-SMES UNIT}

The type of SMES used in the simulation, is a distribution SMES (D-SMES) of $100 \mathrm{~kJ}, 50 \mathrm{~kW}$, proposed and validated by Yunnan Electric Power Grid in China [25]. The D-SMES unit connected to the grid consists of a superconducting coil, one set of 6-pulse bridge converter, a two-winding transformer, a 6-pulse generator, a controller, filters and refrigeration system [26]. Figure 1 shows a diagram of the D-SMES main components. 


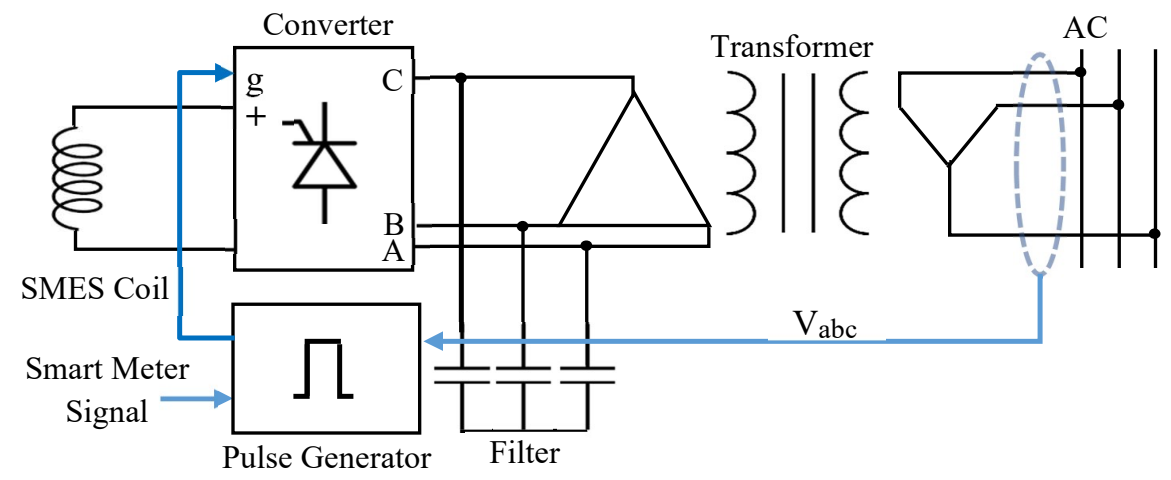

Figure 1 Configuration of DSMES unit

The D-SMES unit can exchange power with the grid by adjusting the delay angle $\alpha$ of the 6-pulse generator. Bidirectional exchange of power controlled directly by a signal delivered from the smart meter to gives the states of charge or discharge of D-SMES unit.

With reference to Figure 1, the rectified voltage $V_{s m}$ across the superconducting coil is given by the following relationship [24]:

$$
V_{s m}=E_{d 0}-X_{c} I_{s m}
$$

Where $X_{c}$ is the switching reactance of the thyristors, $I_{s m}$ is the current flowing through the superconducting coil and $E_{d 0}$ is the no-load rectified voltage which is given by:

$$
E_{d 0}=\frac{3 \sqrt{3}}{\pi} V_{\text {max }} \cos \alpha
$$

Where $V_{\max }$ is the amplitude of the three-phase supply voltage of the bridge and $\alpha$ the firing angle of the thyristors, we will then have for a star coupling of the transformer secondary:

Neglecting the voltage drops due to the switching reactance, the active power exchange with the network is written as:

$$
P_{s m}=V_{s m} I_{s m}=E_{d 0} I_{s m}
$$

In the case of star coupling, the active power is then written in the form:

$$
P_{s m}=E_{d} I_{s m} \cos \alpha
$$

With $E_{d}=\frac{3 \sqrt{3}}{\pi} V_{\text {max }}$.

The energy exchange between the coil and the network $P_{s m}$ is controlled by the variation of the firing angle $\alpha$.

The active power modulation of the SMES unit $P_{\text {smes }}$ is:

$$
P_{\text {smes }}=P_{s m}+P_{s m 0}
$$

Where $P_{s m 0}$ is the initial energy in coil.

And also

$$
P_{\text {sm }}=P_{\text {charg }} * S_{\text {charg }}+P_{\text {discharge }} * S_{\text {discharg }}
$$

with

$$
P_{\text {discharg }}^{\max } \leq P_{s m} \leq P_{\text {charg }}^{\max }
$$

And 


$$
S_{\text {charge }}+S_{\text {discharge }} \leq 1
$$

Where $P_{\text {charge }}$ is the active power charged to the D-SMES, $P_{\text {discharge }}$ is the active power discharged from the D-SMES, $S_{\text {charge }}, S_{\text {discharg }}$ are the control decision to charge or discharge for the SMES respectively. All these values are calculated by the Energy Management System (EMS) and transmitted to the control unit of DSMES.

\section{DESCRIPTON OF THE POWER SYSTEM MODEL}

The power system model considered in this simulation study is depicted in Figure 2.

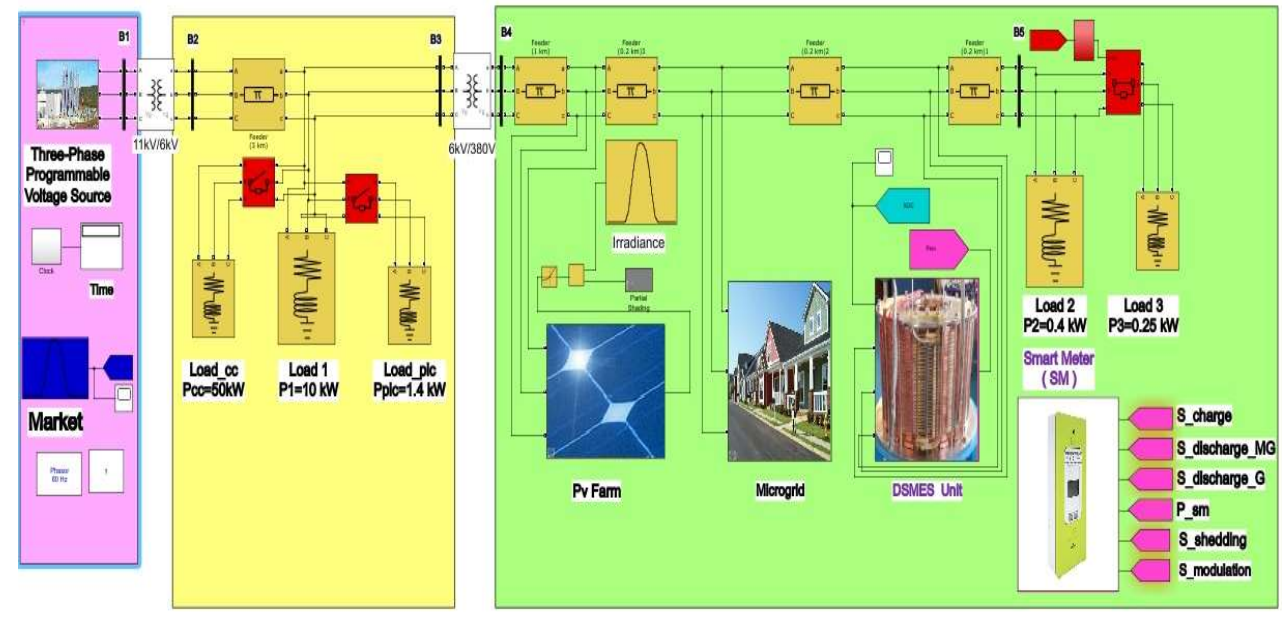

Figure 2 Power system simulation model in MATLAB/Simulink.

The power system sample consists of three areas:

1) Area 1 represents an infinite bus consisting of a swing generator. This area is connected to the distribution zone via a $11 \mathrm{kV} / 6 \mathrm{kV}$ transformer, where the maximum power generated is limited to $P_{\text {gmax }}=11.68$ $\mathrm{kW} / \mathrm{min}$.

2) Area 2 consists of three loads: An industrial load $\left(\operatorname{Load}_{1}\right)$ connected at the extremity of line $L 1$ and two loads $\left(\operatorname{Load}_{c c}, \operatorname{Load}_{\text {pic }}\right)$.

3) Area 3 is a distribution area consisting of four transmission lines ( $L 2, L 3, L 4, L 5)$, a PV farm, a D-SMES unit, a Microgrid and two constant loads $\left(\operatorname{Load}_{2}, \operatorname{Load}_{3}\right)$. In the case of emergency, $\operatorname{Load}_{3}$ can be shed with a signal $S_{\text {shedding }}$ from the Smart Meter. This area is connected to the distribution area with distribution transformer $(6 \mathrm{kV} / 380 \mathrm{~V})$.

\section{ENERGY MANAGEMENT SYSTEM}

Smart meters play a key role in the modernization of the power grid. They create new opportunities for a better management, optimization and control of the power grid at all levels [27]. They allow two-way communication between consumers and energy providers enabling a real-time monitoring of energy usage and more efficient control of power flow and grid assets. With real time bidirectional information transfer, grid operators can easily and optimally manage the electrical power network, and intervene quickly in the event of faults, to ensure better quality of service and enhanced security of the grid [5,28,29]. 
In this study, the smart meter infrastructure is simulated as shown in Figure 3. The smart meters models developed in MATLAB/Simulink have several functionalities such as enable/disable options, calculate power flow, calculate power consumption and cost, switching on and off controllable devices, receive and transfer information, etc.

The EMS receives the energy cost, storage level, energy consumption and the consumption time as state variables, then calculate the optimal power flow, optimal cost and intelligent strategy of energy safety and fault tolerance margins for system [3,7,30,31].

To simplify the study, we focused only on the active power flow, and we defined all power values in $\mathrm{kW} / \mathrm{min}$ for eliminate the problem of time delay related to the operation of electronic and transmission systems. Also we estimate the power lost in the grid to $P_{\text {loss }}=0.68 \mathrm{~kW} / \mathrm{min}$. The smart meter block simulation is shown in Figure 3.

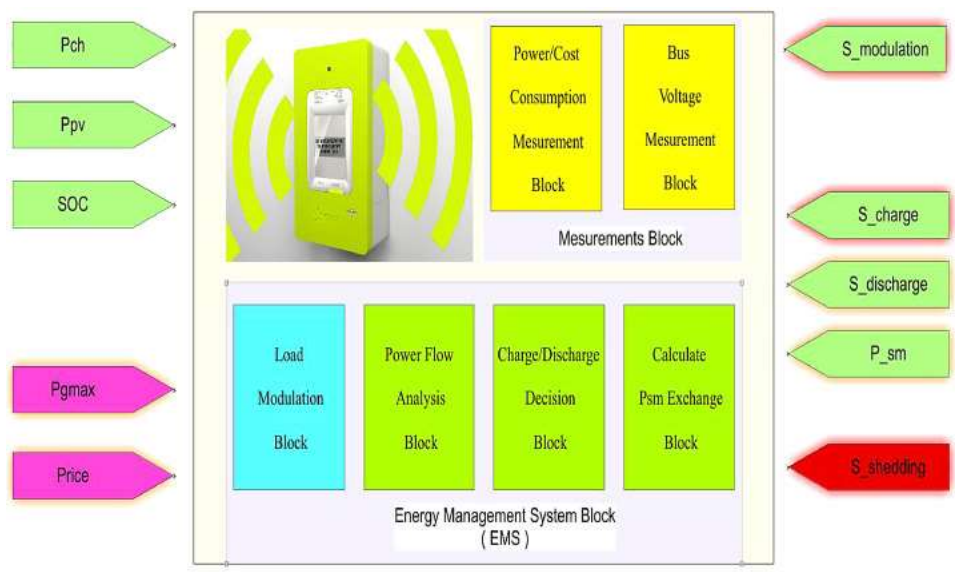

Figure 3 Smart Meter simulation block in MATLAB/Simulink.

The smart meter receives information about power generation $\left(P_{g}\right)$, power of all the connected loads $\left(P_{\text {load }}\right)$, power generation from PV $\left(P_{p v}\right)$, State-Of-Charge (SOC) of the D-SMES and the Real-Time Price (RTP) of energy $\left(S_{\text {price }}\right)$, and calculate the new optimal state of system. The objective is to calculate the Optimal Power Flow $(\mathrm{OPF})$, for a next time period, so that all demands $\left(P_{d i}\right)$ are satisfied at the minimum $\operatorname{cost}\left(C_{M G}(t)\right)$, while satisfying different technical constraints of the network and generators. The standard OPF problem can be defined in the following form:

$$
\left\{\begin{array}{l}
\min \left\{C_{i}(x)\right\} \\
\text { Subject to: } h(x)=0 \text { and } g(x) \leq 0
\end{array}\right.
$$

Where $C_{i}(x)$ is the objective function, $h(x)$ represents the equality constraints, $g(x)$ represents the inequality constraints and $x$ is the vector of the control variables.

The objective function can be expressed in our case, as minimizing the cost of consumption of the real power $C_{M G}(P)$, while avoiding as much as possible, the shedding of loads which can written as:

$$
\left\{\begin{array}{l}
\min \left\{C_{M G}\right\}=\min \left\{\int_{0}^{T} C_{M G}(t)\right\} \\
\text { Subject to }: S_{\text {shedding }}=0
\end{array} \quad \text { for } t \in T\right.
$$

With: 


$$
C_{M G}=\int_{0}^{T} C_{M G}(t)=\int_{0}^{T} P d_{M G}(t) * S_{\text {price }}(t)
$$

And at each $t \in T$ :

$$
P d_{M G}=P_{M G}+P_{p v}+P_{s m}
$$

And:

$$
P_{M G}=P_{c h} * S_{\text {Modulation }}
$$

Where:

$P d_{M G}$ : the demand power of microgrid from grid.

$P_{M G}$ : the demand power of microgrid after modulation.

$P_{c h}$ : the real charge profile demand power of microgrid.

$S_{\text {Modulation }}$ : the modulation signal value.

Notice that:

$$
\begin{cases}S_{\text {Modulatio }} \leq 1 & \text { if modulation enabled } \\ S_{\text {Modulation }}=1 & \text { if modulation disabled }\end{cases}
$$

Finally,

$$
C_{M G}=\int_{0}^{T}\left(P_{c h}(t) * S_{\text {Modulation }}(t)+P_{p v}(t)+P_{s m}(t)\right) * S_{\text {price }}(t) \quad \text { for } t \in T
$$

The second equality constraint condition for $S_{\text {shedding }}$ can be verified by the resolution of the standard OPF problem, described mathematically as an objective with two constraints as:

$$
\left\{\begin{array}{l}
\sum_{P g_{j}}=\sum P d_{i}+P_{\text {loss }} \\
P g_{i}^{\text {min }} \leq P g_{i} \leq P g_{i}^{\text {max }}
\end{array} \quad i, j \in N^{2}\right.
$$

In our case the OPF given by:

$$
\left\{\begin{array}{c}
P g=\sum P d_{i}+P_{\text {loss }} \\
P g \leq P g^{\max }
\end{array} \quad i \in N\right.
$$

With at each $t \in T$ :

$$
P d=P_{\text {load } 1}+P_{c c}+P_{\text {pic }}+P d_{M G}+P_{\text {load } 2}+P_{\text {laod } 3}
$$

From equations (12) and (13):

$$
P d=P_{\text {load } 1}+P_{c c}+P_{\text {pic }}+P_{c h} * S_{\text {Modulation }}+P_{p v}+P_{s m}+P_{\text {load } 2}+P_{\text {laod } 3}
$$

With:

$$
P_{\text {load } 3}=\left\{\begin{array}{cl}
P_{\text {load } 3} & \text { if } S_{\text {shedding }}=0 \\
0 & \text { otherwise }
\end{array}\right.
$$

And the shedding signal given by:

$$
S_{\text {shedding }}= \begin{cases}0 & \text { if } P g \leq P g^{\max } \\ 1 & \text { otherwise }\end{cases}
$$

\section{SIMULATION RESULTS AND DICUSSIONS}

In this study, three situations are simulated and compared, to demonstrate the benefits of using the D-SMES with intelligent control in improving the power quality, optimization of consumption and cost in a Microgrid (MG). 
- Scenario 1: Simulation of the MG without using intelligent control and optimization by maintaining the Smart meter, when the exchange of power from the MG to the Grid is not allowed and the option of disabling load modulation.

- Scenario 2: Simulation of the MG with using intelligent control and optimization with SM, when the exchange of power from the MG to the Grid is allowed, but the option of loads modulation is also disabled.

- Scenario 3: Simulation of the MG with using intelligent control and optimization with SM, and the option of loads modulation is enabled.

In these simulations, we proposed the profiles of power demand in MG, the PV power output and the electrical price consumption in the following figures 4 and 5 .

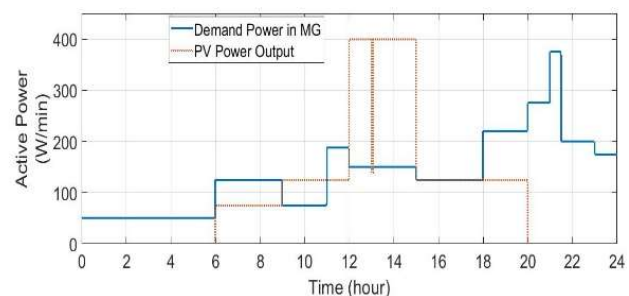

Figure 4 Demand power in MG and PV Output.

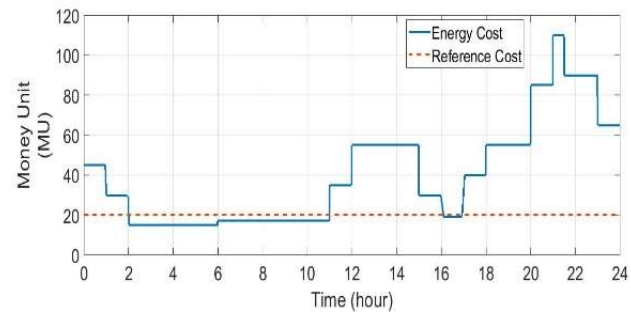

Figure 5 Electrical Price Consumption.

In all cases, we have compared the decision of charge/discharge, the power exchange, the rate of charge of the D-SMES unit and the decision of load shedding. The following figures represent the simulations results for each case:

\subsection{Simulation results for Scenario 1 (without intelligent control)}

In this case, the electricity price and time of consumption are not considered and there isn't any strategy for power flow optimization and consumption. The MG consumes all power demand from the D-SMES unit initially and then starts importing from the grid when the D-SMES unit totally discharged. Also, the D-SMES unit is charged only from the PV panel, and discharges only to the MG, without intervening in overload time in grid.

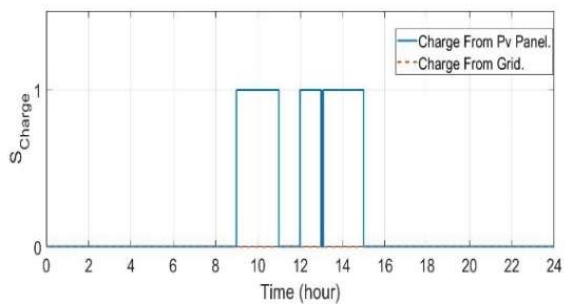

Figure 6 Decision to Charge DSMES Unit.

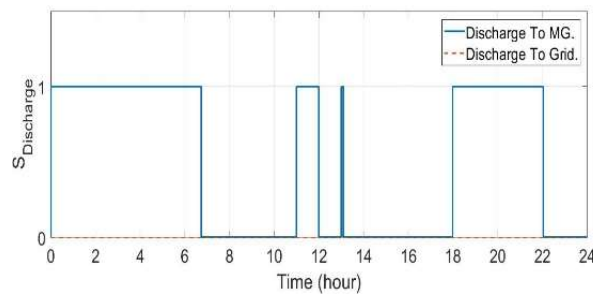

Figure 7 Decision to Discharge DSMES Unit. 


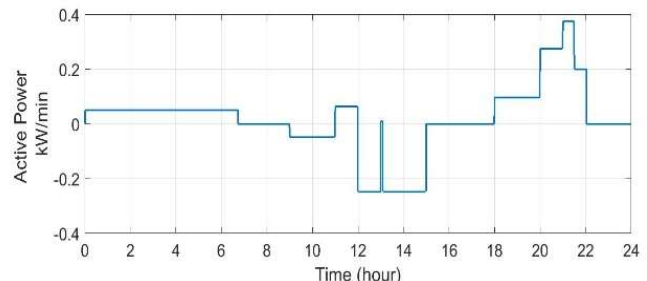

Figure 8 Active Power exchange of DSMES Unit.

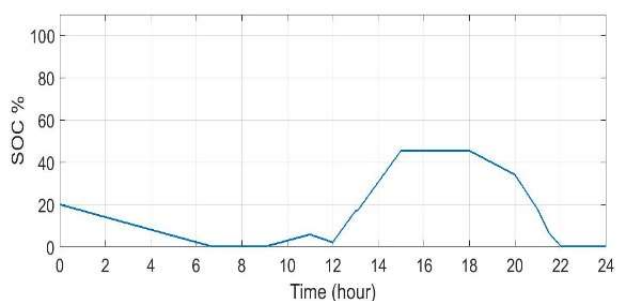

Figure 9 Stat of Charge for DSMES Unit.

With reference to Figures 6, 7, 8 and 9 it can be observed that:

- From 13:00 to 13:05: the D-SMES unit discharges power for respond to overload in PV production when $P_{M G}>P_{p v}$.

- From 14:00 to 14:02: despite that the grid need power and there is excess in PV production, where the DSMES SOC is $30.7 \%$, for that the SM give decision to charge the excess of the PV power production to the D-SMES unit, without intervening in the grid level.

- From 21:00 to 21:30 the power demand in grid higher than the maximum power generate, the D-SMES SOC is $17.3 \%$ and discharge power only to the MG without intervening in the grid level.

- The DSMES unit is charged to a maximum of $45.5 \%$ at 15:00, and totally discharged at 22:02. After that, the $\mathrm{MG}$ consumes the required power directly from the grid with higher price. Figure 10 give the decision of shedding load for 24 hour of simulation:

After simulation, there are two signal of load shedding when the power demand of grid is higher than the maximum power generation in overload time.
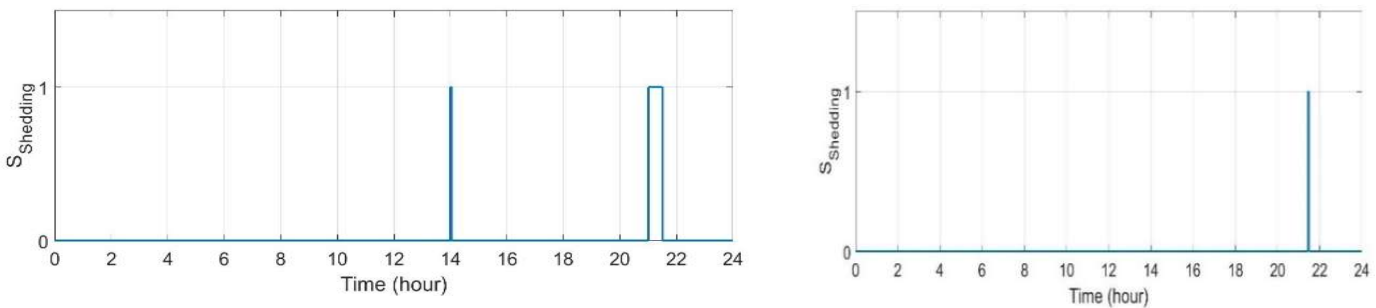

Figure 10 Decision of load shedding.

\subsection{Simulation results for Scenario 2 (without intelligent control and without load modulation)}

In this case, by means of the bidirectional flow of power and information between the SM and the grid, the DSMES unit can be charged from the PV farm and also from the grid when the price is low and can support the grid during overload. All controls decision of SM are generated by solving an optimization problem and making use of historical profiles of power demand across two periods of the day 00:00 - 18:00 and 18:00 - 00:00.

- From 00:00 to 18:00, when the PV power is available and there is no significant overload in power consumption. During this time the SM tries to charge the D-SMES up to $S O C_{r e f}=70 \%$ and not below $S O C_{\text {Min }}=30 \%$, for responsive to the overload time in the second interval of consumption. Preferred to consume from the grid with intermediate cost upper to the cost $t_{r e f}=20 \mathrm{MU}$, to consume from the $S O C_{\text {Min }}$ for security reasons and economics reasons. 
- From 18:00 to 00:00, time of overload consumption, no PV production exist and the consumption price is higher, the only way to respond to the demand power consumption it's to use all the SOC of D-SMES unit. When the SOC is totally consumed, the MG consume from the grid with the overload price.

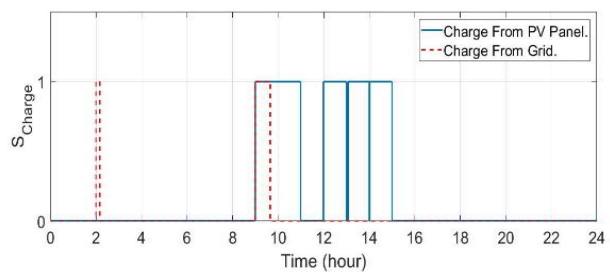

Figure 11 Decision to Charge DSMES Unit.

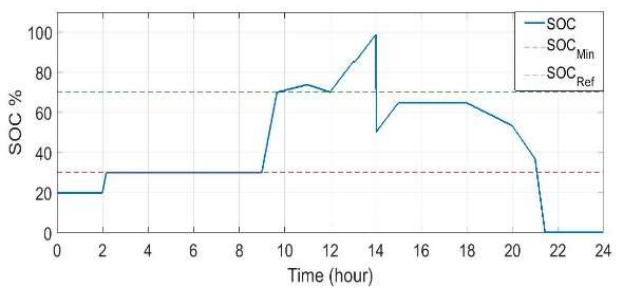

Figure 13 SOC of the D-SMES Unit.

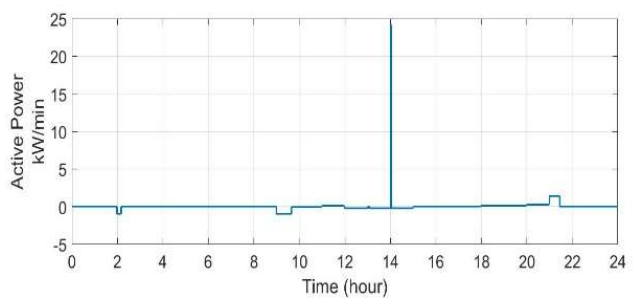

(a)

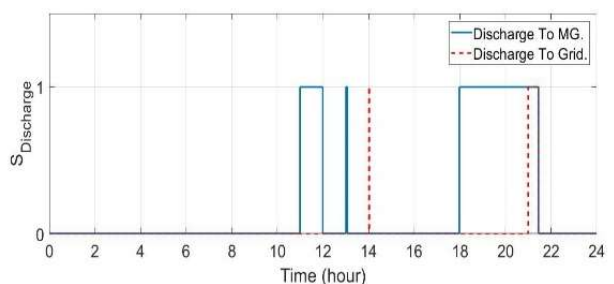

Figure 12 Decision to Discharge DSMES Unit.

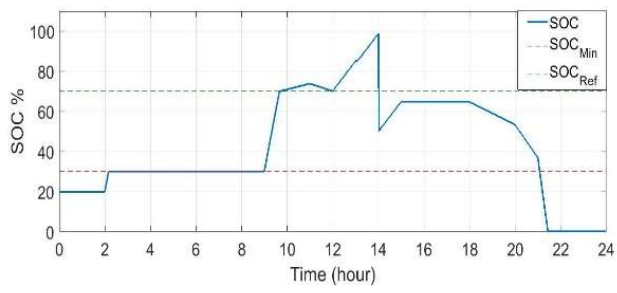

Figure 14 Decision of load shedding.

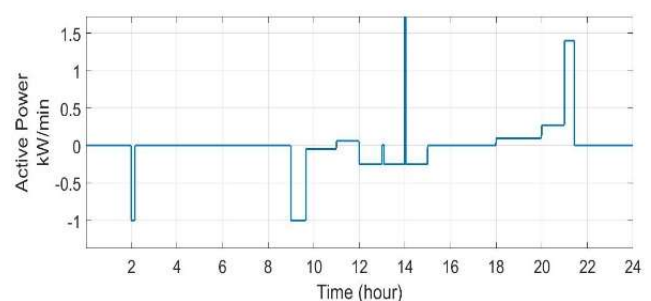

(b)

Figure 15 (a) Active power exchange of the D-SMES Unit (b) Zoom

Based on figures 11 to $15 \mathrm{~b}$, notice that:

- $\quad$ From 00:00 to 02:00: DSMES SOC under the security value (30\%), for that the MG needs the power from the grid to ensure the demand power and the SM make DSMES unit in standby mode because the price of energy is higher than the price-ref.

- $\quad$ From 02:00 to 02:10: at 02:00 the market price value of energy and the SOC of DSMES unit are under the value ref given to the SM. This last one (SM) give decision to charge the DSMES unit to the security value $30 \%$ in the morning time.

- $\quad$ From 2:10 to 9:00: all demand power consumed from the grid, for security reasons, the MG can't use the SOC of DSMES.

- From 09:00 to 11:00: there is an excess of PV production, the SM give signal to DSMES unit to make it in charge mode to store this excess of power. It's the logical decision in local level as the first case of simulation without intelligent control. But in this case, because the market price under the value ref, the SM and for economic 
reasons, preferred to sell energy from the grid for the using in pic time at night, so it give a signal of charge to the DSMES unit.

- At 9:20: to reach the max value of SOC, the SM continues to charge just from the PV production.

- From 11:00 to 12:00: the demand power of MG exceeds the PV production and the energy price is higher than the benchmark, also the SOC is higher to the value security. The SM preferred in this case to consume from the DSMES unit.

- From 12:00 to 15:00: in this time there is an excess of PV production, so the logical decision it's to charge the excess power in the DSMES unit. But in this time there are two overload periods, from 13:00 to 13:05 when there is overload in MG, the SM gives signal to the DSMES unit for intervening and discharge the power to the MG. The second overload time from 14:00 to 14:02, when the overload in the grid it means that the demand power in grid upper to the maximum power generation, so the SM has the information about the SOC of DSMES unit ( $\mathrm{SOC}=99 \%$ ), it gives a decision signal to the DSMES unit to intervening in the grid level and discharge power to the grid. The SOC of DSMES decreased to $50 \%$ at 14:02. After the overload time, the DSMES continues to charge the excess PV production only because the market price is upper to price ref. to get finally SOC $=64.3 \%$.

- $\quad$ From 18:00 to 00:00: it's the second interval of consumption, when the PV production does not existe, and the SM try to use just power stored in the DSMES unit because the market price is upper to the price ref. The DSMES unit can totally discharged in this time.

- At 18:00: the SM gives decision to DSMES unit to started discharge power to the MG until the time of overload in grid from 21:00 to 21:30, the grid can't respond to the demand power, and as the value of stored energy in DSMES unit is $36.3 \%$, the SM gives decision to discharge from the MG and also intervening in grid to ensure the demand power without use shedding load as solution for preserve the system stability.

- At 21:26: the stored power in DSMES unit is totally consumed and the power demand in grid also upper to the maximum power generation, so for keep the balancing power, the SM gives decision to shedding load by eliminate Load3. When the overload finished at 21:30, load3 connected after 04 min of shedding.

- After 21:30: the stored power in DSMES unit equal to 0\%. The MG consume the power demand from the grid with high price.

\subsection{Simulation results for Scenario 3 (with intelligent control and load modulation)}

This case is the same case as the second one, the only deference is the optimization in consumption in time of upper price in market, in faults or overloads times in grid. Figure 16 and figure 17 represented the modulation signal and the demand load profile of MG after modulation.

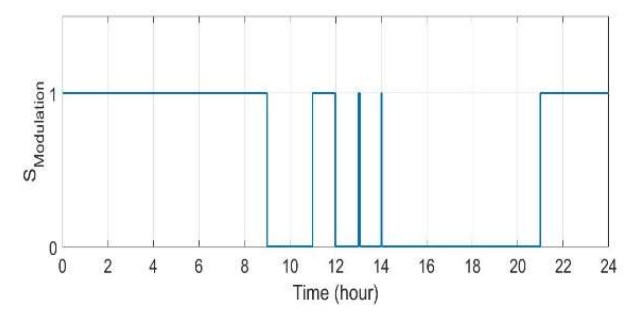

Figure 16 Signal of load modulation in MG.

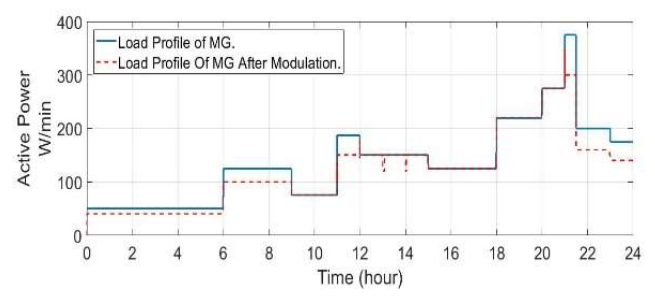

Figure 17 Load demand profile in MG. 
The modulation load is affected in the nighttime from 00:00, when the use of some devices it's not allowed and the demand power in MG upper to PV production. The SM preferred to optimize the power demand from the grid. Also, the option of load modulation enabled in the case of fault or overload in grid when demand power upper to maximum power generation. The SM chooses to decrease the demand power as first solution.

The results of simulation for case 3 in the following figures 18 to $20 \mathrm{~b}$ :

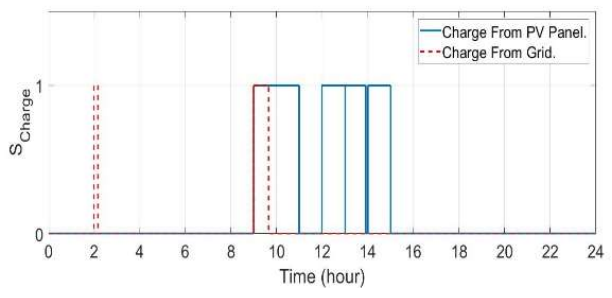

Figure 18 Decision to charge the D-SMES Unit

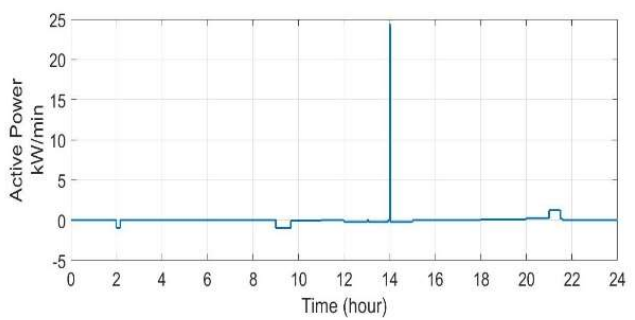

(a)

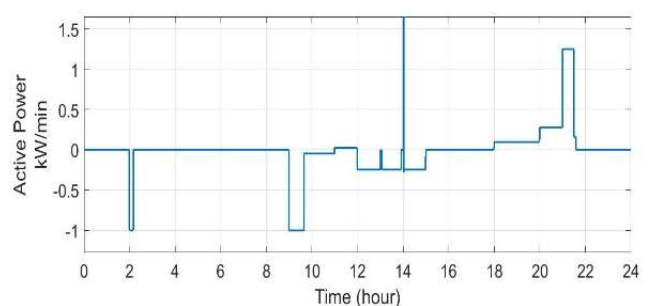

Figure 19 Decision to discharge the D-SMES Unit.

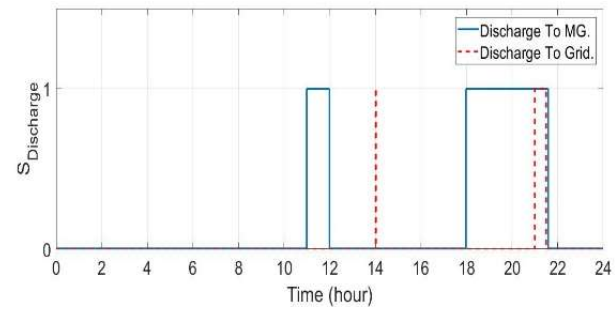

(b)

Figure 20 (a) Active Power exchange of DSMES Unit. (b) Zoom.

Based on the obtained results in this case, we can see that all decision of SM is the same as in case 02 , the only deference that the system with optimization in consumption can respond to the fault in PV production from 13:00 to 13:05 when there isn't discharge from DSMES unit to MG as the second case. And also the system can respond to the overload time from 21:00 to 21:30, when the DSMES unit discharge to the MG and also intervening to the grid without shedding load (figs 21 and 22).

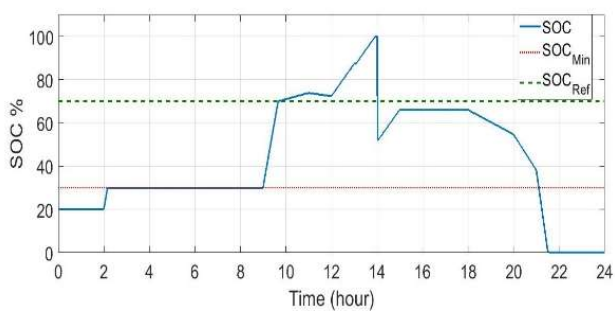

Figure 21 SOC of the D-SMES Unit.

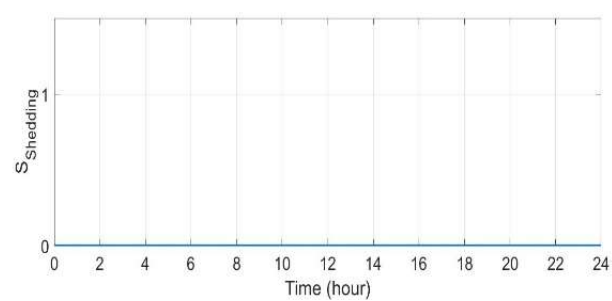

Figure 22 Decision of load shedding.

Table 1 summarizes the duration of load shedding for Load 3 in all scenarios. 
Table 1 Duration of load shedding.

\begin{tabular}{|l|c|c|c|}
\hline \multicolumn{1}{|c|}{ Fault and overload } & Scenario 1 & Scenario 2 & Scenario 3 \\
\hline Fault in the PV farm: 13:00 to 13:05 & $0 \mathrm{~min}$ & $0 \mathrm{~min}$ & $0 \mathrm{~min}$ \\
\hline Overload in the Grid: 14:00 to 14:02 & $2 \mathrm{~min}$ & $0 \mathrm{~min}$ & $0 \mathrm{~min}$ \\
\hline Overload in the Grid: 21:00 to 21:30 & $30 \mathrm{~min}$ & $4 \mathrm{~min}$ & $0 \mathrm{~min}$ \\
\hline
\end{tabular}

This result showed the effectiveness of proposed algorithm maintaining by the smart meter. For the same system and the same scenario, case 03 can preserve the power quality in system without any load shedding decision.

\section{Power consumption and cost results}

In this section, we compare the evolution of power consumption and its cost for all case, figures 23 to 28 presenting the results of simulations:

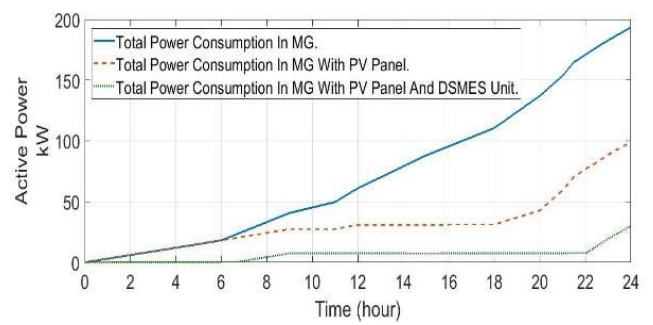

Figure 23 Power consumption in Scenario 1.

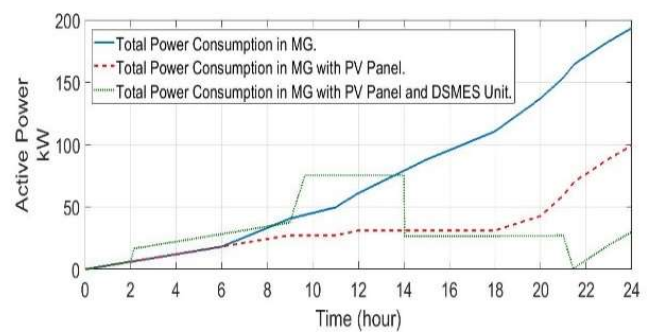

Figure 25 Power consumption in Scenario 2.

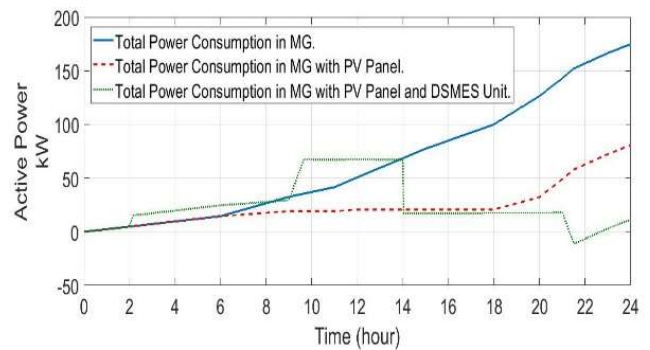

Figure 27 Power consumption in Scenario 3.

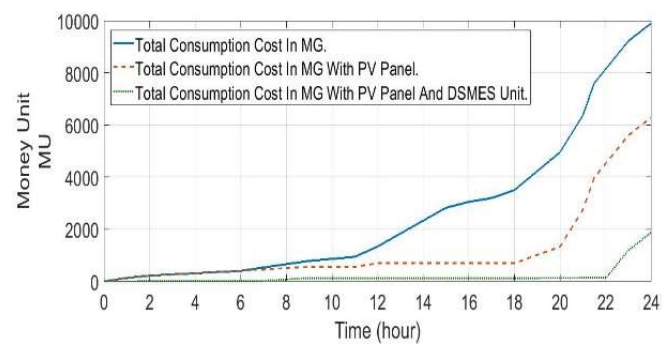

Figure 24 Cost in Scenario 1.

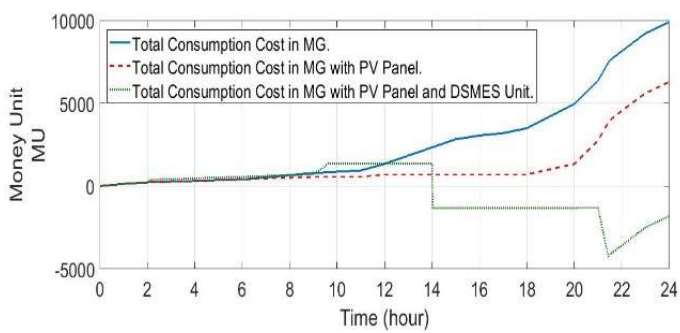

Figure 26 Cost in Scenario 2.

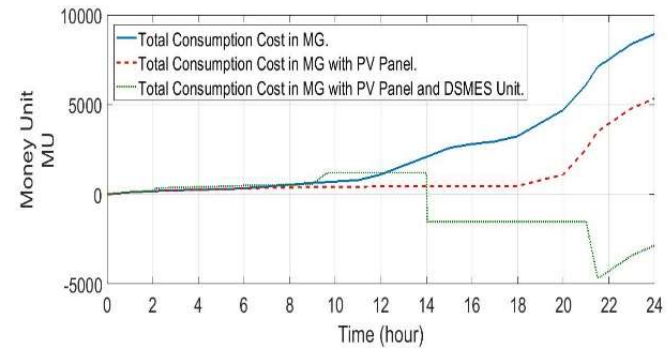

Figure 28 Cost in Scenario 3. 
The results improve the high performance of integration DSMES unit in smart Grid, where the intelligent management of stored power can optimize the power consumption and also economized the cost of consumption. The following Table 02 compared the total power and cost consumption for all cases:

Table 2 Comparison of total power consumption and cost for Scenario 1, 2 and 3.

\begin{tabular}{|c|c|c|c|}
\hline Total consumption & Scenario 1 & Scenario 2 & Scenario 3 \\
\hline Power (kW) & 30 & 30.02 & 11.53 \\
\hline Cost (MU) & +1903 & -1784 & -2838 \\
\hline
\end{tabular}

Greased to the exchange of power with deferent price, the MG intervening to the grid in overload time when price of power is very expensive and charge power in lower price. For that, a very important economical advance for the same power consumption between case 01 and case 02 , the consumer paid an amount of 1903 MU for case 01, however he gains an amount of $1784 \mathrm{MU}$ for case 02.

For case 03, there are less power consumption and more economic benefit, because the consumer uses the load modulation and translate the consumption of same device to time of lower price. He gains an amount of 2838 MU.

\section{Conclusion}

This paper proved, through a three cases study, the usefulness of DSMES unit in smart distribution grid, where two main advances are showed:

Firstly, the results in the Table 01, provide the advance of using intelligent control and optimization of consumption for increased the power quality and the level of security in electrical system. It's the key of the new revolution for smart grid application.

Secondly, the exchange of information in multilevel in smart grid, allow to the Smart meter to use information for get the best technical and economical solution for all consumers with high quality and low cost. Greased to the intelligent algorithm using for ensure the best using of all devices connected to Smart meter. The results for level of stored power in DSMES unit improve the benefit of best use of this device as showing in Table 02 for economical advance.

\section{Appendix}

Studied System Parameters:

Simulation Parameters:

- Time simulation: $\mathrm{T}=01$ day $(24 \mathrm{~h}),(24 * 60)$, Simulation Step (1 min).

- Solver: Ode23tb, Variable step.

$\underline{\text { Area 01: }}$

- Generator: $\mathrm{Vrms}=11 \mathrm{kV}, \mathrm{f}=60 \mathrm{~Hz}$.

- Transformer: Yg, $11 \mathrm{kV} / 6 \mathrm{kV}, 200 \mathrm{kVA}$.

Area 02 :

- Line 1: 3km, $60 \mathrm{~Hz}$, [ r1 r0 ]: [ 0.104 0.357], [ 11 10 ]: [1.048e-3 3.483e-3], [ c1 c0 ]: [ $11.212 \mathrm{e}-09$ 4.8118e-09].

- $\quad$ Load CC: Constant Z: $P_{c c}=25 \mathrm{~kW}$, from 14:00 to 14:02 
- Load pic: Constant $\mathrm{Z}: \mathrm{P}_{\text {pic }}=1 \mathrm{~kW}$, from 21:00 to 21:30.

- Load 1 (Industrial Load): Constant $Z: P_{l o a d}=10 \mathrm{~kW}$.

- Transformer:Yg, 6kV/380V, $20 \mathrm{kVA}$..

Area 03 :

- $\quad$ Line $2: 3 \mathrm{~km}$

- $\quad$ Line $3: 0.2 \mathrm{~km}$

- $\quad$ Line $4: 0.2 \mathrm{~km}$

- $\quad$ Line $5: 0.2 \mathrm{~km}$

$60 \mathrm{~Hz}$, [ r1 r0 ]: [ 0.104 0.357], [ 1110 ]: [1.048e-3 3.483e-3], [ c1 c0 ]: [ $11.212 \mathrm{e}-09$ 4.8118e-09]

- $\quad$ MG : 50 Houses, PF 0.95 .

- DSMES : $100 \mathrm{~kJ} / 50 \mathrm{~kW}$

- Load 2: Constant $Z: P_{\text {load } 2}=0.4 \mathrm{~kW}$

- Load 3: Constant $Z: P_{\text {load } 3}=0.25 \mathrm{~kW}$

\section{References}

[1] O. Olatunde, M.Y. Hassan, M.-.P. Abdullah, H.A. Rahman, Hybrid photovoltaic/small-hydropower microgrid in smart distribution network with grid isolated electric vehicle charging system, J. Energy Stor., 31 (2020).

[2] E. Rosenberg, K.A. Espegren; O. Wicken; E. Holden; M. Ryghaug and K.H. Sørensen, CenSES Energy Demand Projections Towards 2050, A Position Paper prepared by FME CenSES, 2015.

[3] R. Carli, M. Dotoli, J. Jantzen, M. Kristensen, S. Ben Othman, Energy scheduling of a smart microgrid with shared photovoltaic panels and storage: the case of the Ballen marina in Samsø, Energy, 198 (2020).

[4] P. van Zoest, E. Veldman, Z. Lukszo, P.M. Herder, Analysis of future electricity demand and supply in the low voltage distribution grid, Proceedings of the 11th IEEE International Conference on Networking, Sensing and Control, Miami, FL, USA (2014).

[5] K. KusakanaOptimal peer-to-peer energy management between grid-connected prosumers with battery storage and photovoltaic systems, J. Energy Stor., 32 (2020).

[6] S. Zhang, Y. Tang, Optimal schedule of grid-connected residential PV generation systems with battery storages under time-of-use and step tariffs, J. Energy Stor., 23 (2019), pp. 175-182.

[7] M.W. Khan, J. Wang, M. Ma, L. Xiong, P. Li, F. Wu, Optimal energy management and control aspects of distributed microgrid using multi-agent systems, Sustain. Cities Soc., 44 (2019), pp. 855-870.

[8] M. Marzband, H. Alavi, S.-.S. Ghazimirsaeid, H. Uppal, T. Fernando, Optimal energy management system based on stochastic approach for a home Microgrid with integrated responsive load demand and energy storage, Sustain. Cities Soc., 28 (2017), pp. 256-264.

[9] W. Li, M. Rentemeister, J. Badeda, D. Jöst, D. Schulte, D-U. Sauer, Digital twin for battery systems: cloud battery management system with online state-of-charge and state-of-health estimation, J. Energy Stor., 30 (2020).

$[10]$ C. Bordin, O. Mo, Including power management strategies and load profiles in the mathematical optimization of energy storage sizing for fuel consumption reduction in maritime vessels, J. Energy Stor., 23 (2019), pp. 425-441. 
[11] M.H. Amrollahi, S.- M.-T. Bathaee, Techno-economic optimization of hybrid photovoltaic/wind generation together with energy storage system in a stand-alone micro-grid subjected to demand response, Appl. Energy, 202 (2017), pp. 66-77.

[12] S. Baldi, A. Karagevrekis, I.-.T. Michailidis, E.-.B. Kosmatopoulos, Joint energy demand and thermal comfort optimization in photovoltaic-equipped interconnected microgrids, Energy Convers. Manag., 101 (2015), pp. 352-363.

[13] C.D. Korkas, S. Baldi, I. Michailidis, E.-.B. Kosmatopoulos, Occupancy-based demand response and thermal comfort optimization in microgrids with renewable energy sources and energy storage, Appl. Energy, 163 (2016), pp. 93-104.

[14] M.E. Honarmand, V. Hosseinnezhad, M.-.S. Ghazizadeh, F. Wang, P. Siano, A peak-load-reduction-based procedure to manage distribution network expansion by applying process-oriented costing of incoming components, Energy, 186 (2019).

[15] Y. Song, Y. Ding, P. Siano, C. Meinrenken, M. Zheng, G. Strbac, Optimization methods and advanced applications for smart energy systems considering grid interactive demand response, Appl. Energy, 259 (2020).

[16] C. Korkas, S. Baldi, I. Michailidis, E.B. Kosmatopoulos, Intelligent energy and thermal comfort management in grid-connected microgrids with heterogeneous occupancy schedule, Appl. Energy, 149 (2015).

[17] M. Farrokhifar, F.-.H. Aghdam, A. Alahyari, A. Monavari, A. SafariOptimal energy management and sizing of renewable energy and battery systems in residential sectors via a stochastic MILP model, Electr. Power Syst. Res., 187 (2020).

[18]R. Morello, C. De Capua, G. Fulco, S.C. Mukhopadhyay, A smart power meter to monitor energy flow in smart grids: the role of advanced sensing and IoT in the electric grid of the future, IEEE Sens. J. (2017), pp. 1558-1748.

[19]I.F. Siddiqui, S. Uk-J. Lee, A. Abbas, A.K. Bashir, Optimizing lifespan and energy consumption by smart meters in green-cloud-based smart grids, IEEE Access, 5 (2017), pp. 20934-20945.

[20] D-I. Fletcher, R.-.F. Harrison, S. Nallaperuma, TransEnergy - a tool for energy storage optimization, peak power and; energy consumption reduction in DC electric railway systems, J. Energy Stor., 30 (2020).

[21]D. Kolokotsa, N. Kampelis, A. Mavrigiannaki, M. Gentilozzi, F. Paredes, F. Montagnino, L. Venezia, On the integration of the energy storage in smart grids: technologies and applications, Energy Stor. (2019), pp. 125.

[22] T.S. Mahmoud, B.- .S.. Ahmed, M.-.Y. Hassan, The role of intelligent generation control algorithms in optimizing battery energy storage systems size in microgrids: a case study from Western Australia, Energy Convers. Manag., 196 (2019), pp. 1335-1352.

[23] Y.Q. Xing, J.X. Jin, Y.L. Wang, B.X. Du, S.C. Wang, An electric vehicle charging system using an SMES implanted smart grid, IEEE Trans. Appl. Superconduct., 26 (7) (2016).

[24] A.R. Kim, G.-.H. Kim, S. Heo, M. Park, In-K. Yua, H.-.M. Kim, SMES application for frequency control during islanded microgrid operation, Phys. C: Superconduct., 484 (2013), pp. 282-286.

[25] M. Song, J. Shi, Y. Liu, Y. Xu, N. Hu, Y. Tang, L. Ren, J. Li, 100 kJ/50 kW HTS SMES for micro-grid, IEEE Trans. Appl. Superconduct., 25 (3) (2015). 
[26]M. Farahani, A new control strategy of SMES for mitigating sub-synchronous oscillations, Phys. C: Superconduct., 483 (2012), pp. 34-39.

[27]C.A. Marino, M. Marufuzzaman, A microgrid energy management system based on chance-constrained stochastic optimization and big data analytics, Comput. Ind. Eng., 143 (2020).

[28]F. Tooryan, H. HassanzadehFard, E.R. Collins, S. Jin, B. RamezaniOptimization and energy management of distributed energy resources for a hybrid residential microgrid, J. Energy Stor., 30 (2020).

[29] M. Parol, T. Wójtowicz, K. Księżyk, C. Wenge, S. Balischewski, B. Arendarski, Optimum management of power and energy in low voltage microgrids using evolutionary algorithms and energy storage, Electr. Power Energy Syst., 119 (2020).

[30]H.G. Ganjehlou, H. Niaei, A. Jafari, D-O. Aroko, M. Marzband, T. Fernando, A novel techno-economic multi-level optimization in home-microgrids with coalition formation capability, Sustain. Cities Soc., 60 (2020).

[31] R. Hemmati, H. Saboori, P. Siano, Coordinated short-term scheduling and long-term expansion planning in microgrids incorporating renewable energy resources and energy storage systems, Energy, 134 (2017), pp. 699-708. 